BMJ Open Sport \& Exercise Medicine

\title{
Declining fitness and physical education lessons in UK adolescents
}

Benjamin David Weedon (D) , ${ }^{1}$ Francesca Liu, ${ }^{1}$ Wala Mahmoud, ${ }^{1}$ Samuel Joseph Burden (D) , ${ }^{1}$ Luke Whaymand, ${ }^{1}$ Patrick Esser, ${ }^{1}$ Johnny Collett (D) , ${ }^{1}$ Hooshang Izadi, ${ }^{2}$ Shawn Joshi, ${ }^{3}$ Andy Meaney, ${ }^{1}$ Anne Delextrat, ${ }^{1}$ Steve Kemp, ${ }^{4}$ Alexander Jones, ${ }^{5}$ Helen Dawes ${ }^{6}$

To cite: Weedon BD, Liu F, Mahmoud W, et al. Declining fitness and physical education lessons in UK adolescents. BMJ Open Sport \& Exercise Medicine 2022;8:e001165. doi:10.1136/ bmjsem-2021-001165

- Additional supplemental material is published online only. To view, please visit the journal online (http://dx.doi. org/10.1136/bmjsem-2021001165).

Accepted 23 December 2021

Check for updates

(C) Author(s) (or their employer(s)) 2022. Re-use permitted under CC BY-NC. No commercial re-use. See rights and permissions. Published by BMJ.

${ }^{1}$ Centre for Movement, Occupational and Rehabilitation Sciences (MOReS), 0xford Brookes University Faculty of Health and Life Sciences, Oxford, UK

${ }^{2}$ School of Engineering, Computing and Mathematics, Oxford Brookes University Faculty of Technology, Design and Environment, Oxford, UK ${ }^{3}$ School of Biomedical Engineering, Science and Health Systems, Drexel University, Philadelphia, Pennsylvania, USA ${ }^{4}$ British Fencing, Oxford, UK ${ }^{5}$ Department of Paediatrics, University of Oxford, Oxford, UK ${ }^{6}$ Exeter College of Medicine and Health, University of Exeter, Exeter, UK

Correspondence to Benjamin David Weedon; b.weedon@brookes.ac.uk

\section{ABSTRACT}

Objectives The objective was to determine recent cross-sectional trends in health-related fitness (HRF) in secondary school students by studying the 13-14 years old age group repeatedly over 6 years, considering parallel national trends in physical education (PE).

Methods Height, weight, broad jump, grip strength, $20 \mathrm{~m}$ shuttle run and throwing and catching skills were measured by the same research team using standardised techniques from 2014 to 2019. Trends in these HRF measures were assessed by linear regression, adjusting for school, sex and height. Interactions with fitness and body mass index (BMI) were tested. The number of PE lessons reported in the UK Annual School Workforce Census between 2010 and 2019 for all state-funded secondary schools was analysed.

Results Grip strength $(B=-0.60,95 \% \mathrm{Cl}-0.78$ to $-0.41)$, broad jump ( $B=-1.16,95 \% \mathrm{Cl}-1.99$ to -0.34$)$, $20 \mathrm{~m}$ shuttle run $(B=-1.85,95 \% \mathrm{Cl}-2.58$ to -1.12$)$ and throwing and catching skills $(B=-0.12,95 \% \mathrm{Cl}-0.15$ to -0.08 ) declined significantly over the study period. There was a greater reduction in broad jump and grip strength in adolescents with low fitness and a greater reduction in fitness and motor competence in adolescents with normal BMI. These declines coincided with a $16 \%$ reduction nationally in secondary school PE between 2010 (333 800 hours) and 2019 (280 725 hours).

Conclusion Adolescent HRF has declined in recent years, in parallel with PE lessons. Declines were observed across all young people and particularly those of low fitness and normal BMI. To reach the majority of young people, policy makers could increase PE in schools to increase activity and prevent worsening fitness and health in future generations.

\section{INTRODUCTION}

Muscle strength and cardiorespiratory fitness (CRF) are related to cardiovascular disease. ${ }^{1}$ CRF and muscle strength can be modified through activities. Thus, the importance of achieving a physically active lifestyle that incorporates activity of a high enough intensity in adolescence to improve CRF and muscle strength is critical for healthy development and the prevention of disease in later life. ${ }^{2}$ The importance of other factors, including

\section{Key messages}

What is already known

- Health-related fitness measures have been declining in primary schoolchildren.

What are the new findings

- Adolescent health and fitness measures have decreased from 2014 to 2019.

- Adolescents with low cardiorespiratory fitness (CRF) show a greater reduction in muscle strength and power compared with adolescents with high CRF.

- Normal-weight adolescents show a greater reduction in CRF and motor competence compared with overweight/obese adolescents.

motor competence (MC) and fundamental sports skills during childhood and adolescence, is emergent as determinants that relate to both initial engagement and longer term participation in physical activity (PA) and sport. ${ }^{3}$ Indeed, the relationship between $\mathrm{MC}$ and PA has been described as reciprocal in nature whereby MC and the individual's perception of skill affect their ability and confidence to participate in PA. ${ }^{45}$ This may affect CRF and muscle strength. ${ }^{56} \mathrm{MC}$, muscle strength and cardiovascular fitness ${ }^{7}$ may be vital for achieving better cardiovascular and metabolic health, and for reducing the risk of non-communicable diseases such as hypertension, diabetes and obesity in later life. ${ }^{8}$

School is a critical period whereby MC, sporting skills, strength, power and fitness are built in all young people. ${ }^{9} 10$ However more recently, as PA has been documented to decline with age, ${ }^{11}$ particularly when children transfer to secondary school, ${ }^{12}$ there is a need to systematically monitor muscle strength, CRF and MC in school-age students. To date, there is little information on these measures in secondary schoolchildren and a need to assess these alongside health markers in all school-age children. ${ }^{13}$

Most young people attend school by statute and limited evidence indicates that 
the majority of school-age students accumulate most activity within school physical education (PE), which also provides an opportunity for regular measurements of fitness and health. ${ }^{14} 15$ Therefore, schools are an important site both for achieving and monitoring, health and fitness profiles, given evidence of recent increases in adolescent obesity, ${ }^{16}$ associated childhood diseases of inactivity ${ }^{17-19}$ and the importance of PE to the activity profiles of most students. We set out to determine recent cross-sectional trends in fitness and health indicators for secondary school students and whether parallel national trends in PE lesson time could offer a possible explanation.

\section{MATERIALS AND METHODS}

Data on height, weight, broad jump, grip strength, $20 \mathrm{~m}$ shuttle run and throwing and catching skills were collected by the same research team using standardised techniques in adolescents aged 13-14years (UK Year 9) over 6 years from 2014 to 2019. A representative sample of three schools from the Oxfordshire region were contacted, covering a broad socioeconomic demographic, and were enrolled in the study, with formal consent from the head teacher. Measurements were carried out as part of enhanced PE lessons at the schools. These lessons formed part of the screening process to recruit participants into three clinical studies (Exploring the Impact and Feasibility of a Pathway to Sport and Long-term Participation in Young People (EPIC; NCT02517333), The Rhythmic Motor Learning in Children with Developmental Coordination Disorders (EPIC2; NCT03150784) and the Oxfordshire Sedentariness, Obesity and Cardiometabolic Risk in Adolescents-A Trial of Exercise in Schools (OxSOCRATES; NCT04118543)). These studies involved public input at the design, conduct and dissemination stages.

\section{Setting}

Each school sent a comprehensive information sheet, prepared by the research team and reviewed by the relevant ethics board, to all parents. The schools were custodians of the data and the parents or guardians were asked by their school to complete a form if they objected to their child's anonymised data being analysed by the research team (opt-out informed consent). The average opt-out across all three schools was $<5 \%$.

\section{Participants}

All students were enrolled in Year 9 at the start of the academic year of 2014 or each subsequent year until 2019. Exclusion criteria consisted of any known medical conditions that could explain deficits in movement or the inability to participate in general PA. These included pathology in cognitive, neurological, musculoskeletal, behavioural or visual function. This was screened using a Physical Activity Readiness Questionnaire. ${ }^{20}$

\section{Procedure}

Data collection took place in each school's sports hall during timetabled PE lessons. Each exercise measure was set up at individual stations and the students rotated between them in groups of 4-5. Each station was controlled by an experienced researcher from Oxford Brookes University, with each session supervised by two PE teachers from the school. Not all measurements were carried out at each time point. Data were not collected for the $20 \mathrm{~m}$ shuttle run, the ball catching task and grip strength in 2014. Furthermore, there were no broad jump data in 2018.

\section{Measures}

Height and weight were measured with a portable Harpenden Stadiometer (Holtain, Crymych, UK) and a SECA medical 770 digital floor scale (SECA, Hamburg, Germany), respectively. Participants were dressed in light sports clothing and were instructed to remove their shoes. Height and weight were used to calculate body mass index (BMI), which is presented as age and sex-independent z-scores (WHO). ${ }^{21} \mathrm{~A}$ battery of healthrelated fitness (HRF) measures was then assessed, including grip strength, broad jump, CRF and MC.

Grip strength was used as a proxy of total muscle strength as they are strongly correlated in adolescents. ${ }^{22}$ The Takei TKK 5001 hand-held dynamometer (P\&A Medical, Chorley, UK) was used to evaluate the highest grip strength from a maximum of three attempts. Each participant was instructed to squeeze the dynamometer as hard as possible, while they were in a standing position with their elbow fully extended and their arm resting comfortably by their side.

Power was measured using the broad jump, as it has been strongly correlated with a one-repetition maximal leg extension test. ${ }^{23}$ Participants were instructed to stand with both feet behind a marked line and jump as far as possible, landing with their feet together. The longest jump out of two attempts was recorded.

CRF was measured using the $20 \mathrm{~m}$ shuttle run test. ${ }^{24}{ }^{25}$ Participants were instructed to run back and forth between two markers that were $20 \mathrm{~m}$ apart. The time required to run between each marker became shorter as the test progressed, requiring participants to run faster. The participants were verbally encouraged to produce a maximal effort and were withdrawn from the test when they failed to reach the marker within the allotted time on three consecutive occasions, or they withdrew from the test themselves. The total number of shuttles that they achieved was recorded as their score.

Over the study period, two very similar throwing and catching tasks were used to assess upper limb MC. The first was the alternate hand ball toss. ${ }^{26}$ In this, each participant threw a tennis ball in an underarm action against a wall and attempted to catch it with the opposite hand. The number of successful catches in $30 \mathrm{~s}$ was recorded. The second was the "catching with one hand' measure from the Movement Assessment Battery for Children-2 age band 3 (11-16 years). ${ }^{27}{ }^{28}$ In this, each participant threw a tennis ball with one hand at a wall and attempted to catch it with the same hand. 
The number of successful catches, out of 10 attempts for each hand, was recorded. Although these two assessments differ slightly in their difficulty, they are highly correlated. Therefore, their rank order would be expected to be similar or the same in most populations. On this basis, we converted each measure to their z-scores (SD score) so that rank order could be compared between these groups.

The total number of hours dedicated to teaching PE was collected from the UK Annual School Workforce Census. ${ }^{29}$ In this census, all state (UK)-funded secondary schools reported the total hours of PE lessons taught each year to students from year 7 to year 13 (11-17 years old).

\section{Statistical analysis}

Statistical analysis was performed using STATA (V.16.1, StataCorp, College Station, Texas). All data were found to be normally distributed on visual inspection of histogram plots. Little's missing completely at random (MCAR) test was used to assess the missingness of the data. ${ }^{30}$ Independent t-tests were used to assess the difference in HRF measures between sexes. Linear regressions were performed to assess the temporal trends of each HRF measure. These relationships were also assessed for interactions with fitness and BMI z-score over time. Each model was adjusted for school ${ }^{31}$ and sex because school catchment areas differed by Index of Multiple Deprivation (IMD). ${ }^{32}$ Grip strength, broad jump and ball catching were all additionally adjusted for height to account for inherent advantages of greater physical size in these measures. CRF was split into low (30 shuttles), medium (50 shuttles) and high (70 shuttles) tertiles, and BMI categories were determined by WHO thresholds $(<1$ $z$-score=normal weight, $\geq 1$ to 2 z-scores=overweight and $>2 \mathrm{z}$-scores $=$ obese). Statistical significance was defined as $\mathrm{p}<0.05$.

\section{Patient and public involvement}

Patients and/or the public were involved in the design, or conduct, or reporting, or dissemination plans of this research.

\section{RESULTS}

A total of 2651 participants took part in school screening assessments between September 2014 and December 2019. A summary of HRF measures is given in table 1 , showing the expected sex differences in height, strength, fitness and upper limb MC. There was a statistically significant difference in BMI z-scores between sexes, but the magnitude of this was clinically unimportant. All participants had data on sex and $94 \%$ had complete data on height and weight. In 2014, only broad jump was assessed and was recorded for $84 \%$ of participants. In 2018, all HRF measures except broad jump were assessed and were available for $62 \%$ of participants that year. In other years, $80.4 \%$ of participants had complete HRF data sets. Some missing data were due to lesson time limitations. For all years except 2014 and 2018, we tested for data MCAR and showed that the missingness of data on sex $(\mathrm{p}=0.16)$, BMI $(\mathrm{p}=0.50)$ and fitness $(\mathrm{p}=0.17)$ was random.

Across the three schools, IMD ranged from the 1st to the 4th quintile and regression analyses were adjusted accordingly. Analyses were also adjusted for sex, given significant sex differences in HRF measures (table 1). Grip strength, broad jump and ball catching were additionally adjusted for height.

Figure 1 shows the total amount of time dedicated to PE lessons across all state-funded secondary schools in the UK from 2010 to 2019. In total, PE hours decreased by 53075 (16\%) from 333800 in 2010 to 280725 in 2019. We chose to report a wider temporal window than is encompassed by our HRF assessments, to better illustrate the overall trend and because declines in taught $\mathrm{PE}$ in earlier years may have impacted on our students before they reached Year 9.

Table 2 reports the linear trends of each HRF measure over time. Height and weight have increased significantly since 2014. There was no significant trend in BMI z-scores over the same period. Grip strength, broad jump and total shuttles reduced significantly with time. Thus, strength, power and CRF levels have all decreased in adolescents aged 13-14years since 2014-2015 with a parallel increase in body weight and height but not in adiposity. Furthermore, upper limb MC has significantly decreased since

Table 1 Summary characteristics

\begin{tabular}{|c|c|c|c|c|c|}
\hline & \multicolumn{2}{|l|}{ Girls } & \multicolumn{2}{|l|}{ Boys } & \multirow[b]{2}{*}{$P$ value } \\
\hline & $\mathbf{n}$ & Mean \pm SD & $\mathbf{n}$ & Mean \pm SD & \\
\hline Weight (kg) & 1113 & $54.9 \pm 12.0$ & 1386 & $55.0 \pm 12.5$ & 0.78 \\
\hline BMI z-score (WHO) & 1111 & $0.3 \pm 1.2$ & 1380 & $0.2 \pm 1.3$ & 0.008 \\
\hline Grip strength (kg) & 1144 & $24.4 \pm 5.4$ & 1381 & $27.1 \pm 7.4$ & $<0.001$ \\
\hline Total shuttles & 1065 & $43.1 \pm 19.4$ & 1251 & $62.3 \pm 26.2$ & $<0.001$ \\
\hline Ball catching (SDS) & 947 & $-0.4 \pm 1$ & 1148 & $0.4 \pm 0.9$ & $<0.001$ \\
\hline
\end{tabular}

BMI, body mass index; $\mathrm{n}$, sample size; SDS, SD score. 


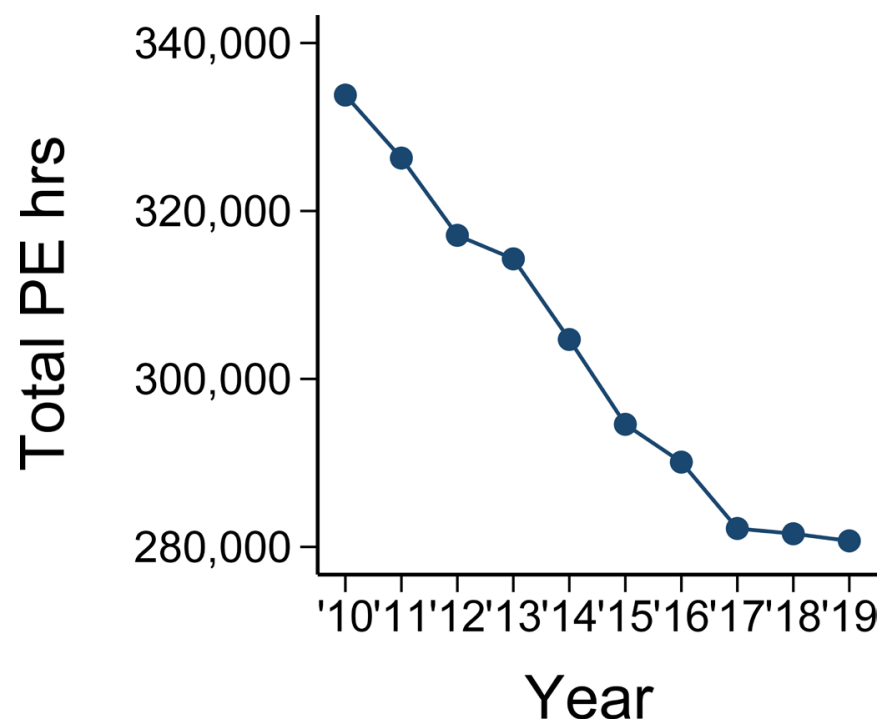

Figure 1 The total hours of taught physical education (PE) lessons for secondary school (11-17 years old) students from 2010 to 2019.

2015. To illustrate these trends, the marginal means of each HRF measure are plotted by sex in figure 2 .

The interactions between CRF and the trends of HRF measures are illustrated for three tertiles of CRF in figure 3. There were significant interactions for broad jump and grip strength, with the steeper declines in these measures for the low CRF segment of the population compared with those with higher CRF. Figure 4 shows the interactions between BMI and year for each HRF measure. There were significant interactions for $\mathrm{CRF}$ and MC, with steeper declines in these measures in the normal-weight segment of the population and no real change in those who were overweight or obese.

\section{DISCUSSION}

Over 6 years, from 2014 to 2019, we observed a declining trend in CRF, MC, muscle strength and power, alongside positive trends for weight and height, but not BMI, in UK adolescents. These changes in HRF measures coincided with a reduction in PA through taught PE hours across UK secondary schools. Our findings are the first
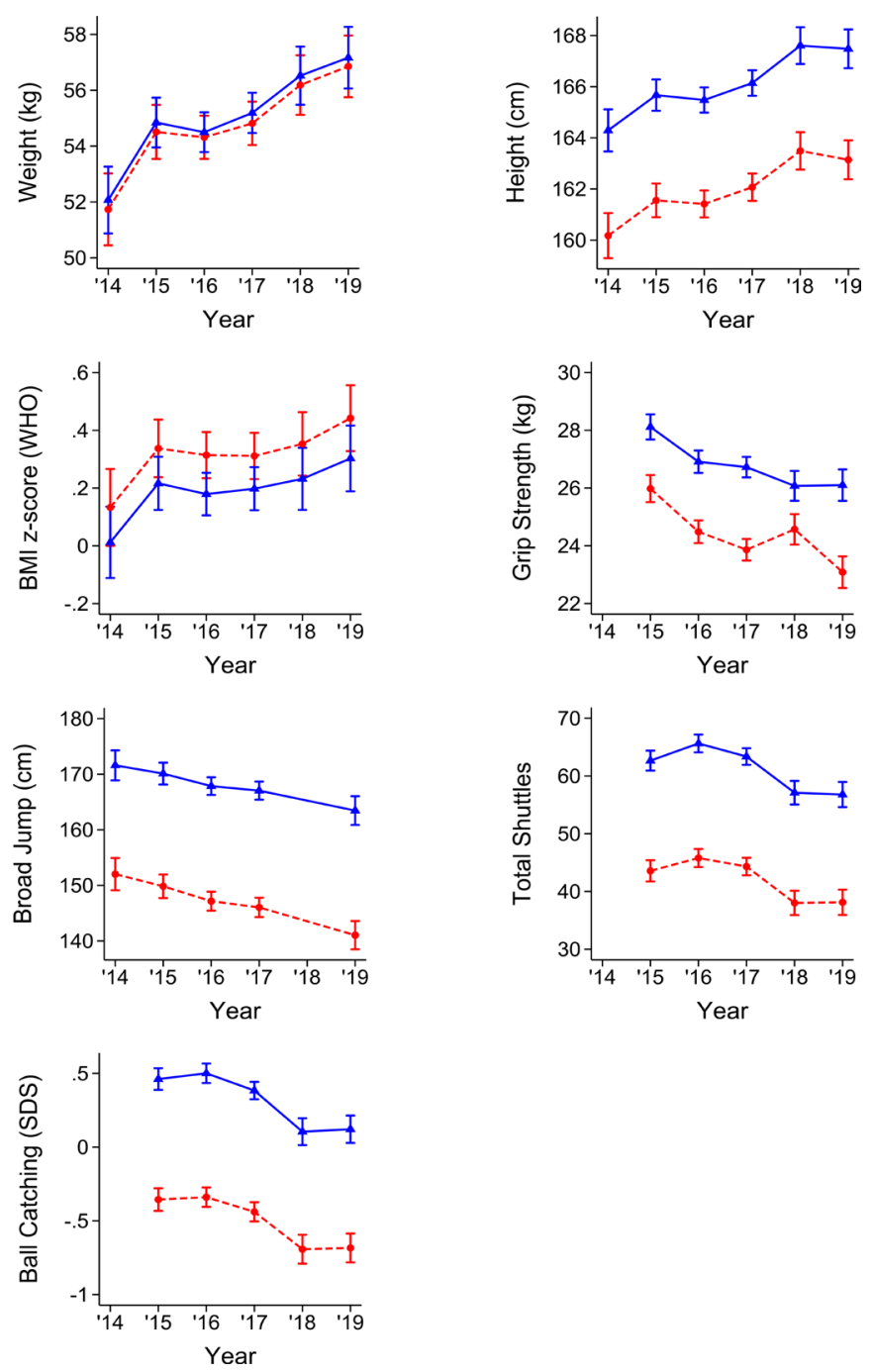

Figure 2 Estimated marginal means and 95\% Cls of healthrelated fitness measures from 2014 to 2019. The solid blue lines and triangles represent boys and the red dashed lines and circles represent girls. BMI, body mass index; SDS, SD score.

demonstration in adolescents that the declines in HRF measures that are similar to those that have been reported in younger children are also occurring in UK secondary schools and may in part be related to declining PE. ${ }^{13} 3334$

Table 2 Trend analysis of linear regressions of health and fitness measures over time for adolescents aged 13-14 years

\begin{tabular}{|c|c|c|c|c|}
\hline & $B$ coef & St $\beta$ coef & $95 \% \mathrm{Cl}$ & $P$ value \\
\hline Height $(\mathrm{cm})^{\star}$ & 0.65 & 0.11 & 0.40 to 0.89 & $<0.001$ \\
\hline Weight $(\mathrm{kg})^{\star}$ & 0.56 & 0.07 & 0.21 to 0.91 & 0.002 \\
\hline BMI z-score $(\mathrm{WHO})^{\star}$ & 0.01 & 0.01 & -0.03 to 0.04 & 0.78 \\
\hline Grip strength $(\mathrm{kg}) \dagger$ & -0.60 & -0.12 & -0.78 to -0.41 & $<0.001$ \\
\hline Broad jump (cm)† & -1.16 & -0.06 & -1.99 to -0.34 & 0.006 \\
\hline Total shuttles* & -1.85 & -0.10 & -2.58 to -1.12 & $<0.001$ \\
\hline Ball catching (SDS)† & -0.12 & -0.16 & -0.15 to -0.08 & $<0.001$ \\
\hline
\end{tabular}

$95 \% \mathrm{Cl}$ of the unstandardised beta coefficient.

${ }^{*}$ Adjusted for school and sex.

†Adjusted for school, sex and height.

$B$ coef, unstandardised beta coefficient; BMI, body mass index; SDS, SD score; St $\beta$ coef, standardised beta coefficient. 

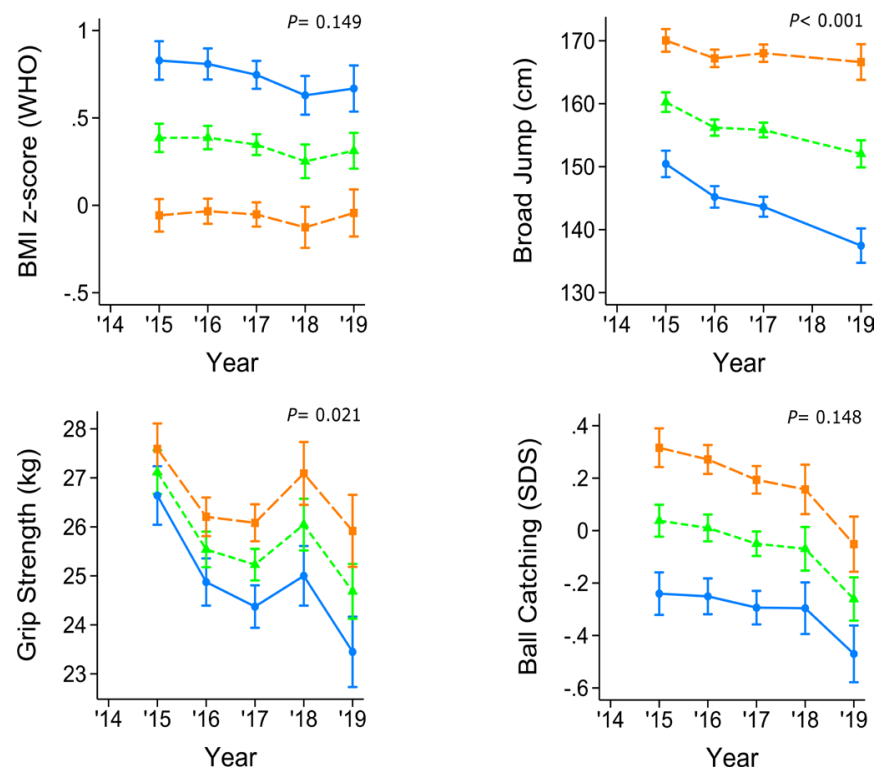

Figure 3 Estimated marginal means and $95 \% \mathrm{Cls}$ illustrating the interactions between fitness and year for three fitness tertiles: low fitness (blue circles with solid line), moderate fitness (green triangles with short dashes) and high fitness (orange squares with long dashes). BMI, body mass index; SDS, SD score.

We demonstrate declines in MC, which have not been reported before, and which are likely to impact on future exercise habits and cardiorespiratory health in these year groups. Notably, we found that over this period, fitness and $\mathrm{MC}$ have been declining more in normal-weight young people than their overweight peers. This may be particularly important as their normal weight could
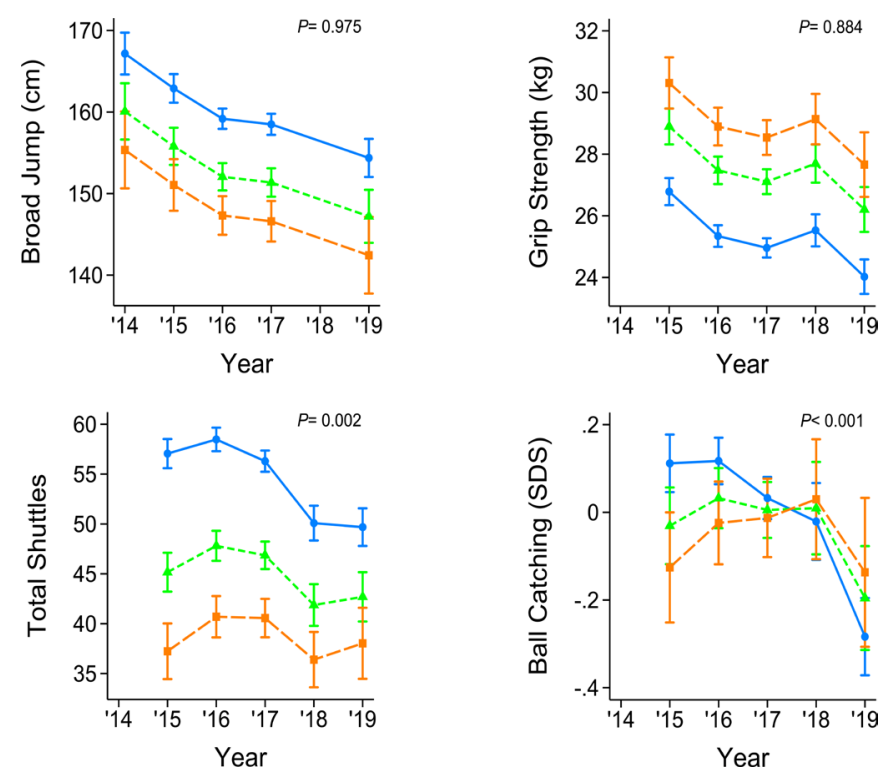

Figure 4 Estimated marginal means and 95\% Cls illustrating the interactions for body mass index (BMI) and year for three BMI categories: obese (orange squares with long dashes), overweight (green triangles with short dashes) and normal weight (blue circles with solid line). SDS, SD score. mean that their declining health status is less likely to be detected. We also found that strength and power are declining more steeply in people with low CRF compared with those with higher CRF. One possible reason for this is that such individuals may not participate in sport or fitness-related activities outside of school and thus be entirely reliant on the structured exercise training that PE delivers. Considering that adolescent measures of cardiorespiratory and muscle fitness are strongly related to morbidity in adulthood, ${ }^{35}{ }^{36}$ and are better predictors than similar measures made earlier in life, ${ }^{37}$ our research reveals a worrying trend in HRF that may cause burgeoning health problems in future adult populations.

Low-grip strength and power in children and adolescents are four times more likely to persist into adulthood compared with high strength and power. ${ }^{37}$ Previous evidence indicated that a reduction of 1 SD in childhood grip strength is associated with $34 \%$ greater incidence of pre-diabetes or type 2 diabetes in adulthood. ${ }^{38}$ Based on this, our finding of a $0.2 \mathrm{SD}$ reduction in adolescent grip strength over the last 5 years might be expected to result in a $7 \%$ increase in pre-diabetes or type 2 diabetes in future adult populations. Given that the annual UK economic burden of these disorders was estimated at $£ 11.7$ billion in 2012 and is likely to have risen since, ${ }^{39}$ this decline in adolescent HRF would correspond to at least $£ 820$ million greater costs per year in future populations if it is representative of a UK-wide change. This highlights an urgent need for regulated HRF monitoring in schools and political/educational interventions designed to reverse the trends illustrated here.

Acquiring muscle power in adolescence has also been shown to reduce the risk of adult metabolic syndrome. ${ }^{36}$ Evidence from Fraser $e t a l^{36}$ suggests adolescents with high muscle power have a lower relative risk $(0.26)$ of acquiring metabolic syndrome in adulthood, compared with adolescents with low muscle power. Our current study reports a $0.3 \mathrm{SD}$ decline in adolescent muscle power over the past 6years and this, in combination with low muscle strength, may have an additive effect on future morbidity. Our current findings clearly highlight a need to assess children and adolescent muscle strength and power and to consistently monitor them over time. ${ }^{13}$

A number of different factors such as PA enjoyment, selfperceived MC and extracurricular factors such as access to supervised PA and exercise equipment may explain these reductions in fitness, $\mathrm{MC}$ and muscle strength and power. ${ }^{4041}$ A number of studies have reported that very few children and adolescents are meeting the recommended guidelines for daily PA. ${ }^{42}$ Part of this inability to meet the guidelines may be as a result of reduced opportunities for young people to be physically active. We propose that one environment where all children and adolescents spend the majority of their time and have access to regular PA is school. Data suggest that school is where the majority of PA is performed by children and adolescents and that this is largely in PE lessons. ${ }^{15}$ These PE lessons provide young people with the opportunity for regular PA and provide 
greater exposure to vigorous forms of PA, which yield better health outcomes compared with moderate forms of PA. ${ }^{14}$ Structured PE lessons may also train students better in MC and coordination skills that are important for engendering a desire to exercise outside of PE and thus have extended benefits. Our study is the first to report that the number of taught PE lessons has declined continuously and steeply over the past decade. Although our study was not designed to test the impact of PE lessons on HRF directly, it seems empirically unlikely that there would be no detrimental effects of declining exposure to PE, given the well-known benefits of exercise. These reductions in HRF measures may have been further exacerbated by a change in the type of PE lessons provided. ${ }^{43}$ Evidence from the Fit to Study project indicated that very few students are performing any significant degree of PA within the PE lesson and the majority of lessons taught are ones in which the lowest levels of PA and exercise intensity are recorded. ${ }^{43}$ This should lead to further research exploring, which PE lessons produce the highest amount of PA while allowing the students to learn the required fundamental movement skills.

\section{Strengths and limitations}

Our study has some notable strengths and limitations. The sample size was large and addressed whole-year groups at the same age over up to 6 years in schools that together represent a broad socioeconomic section of society. However, the samples were all drawn from a single county and may, therefore, not be representative of changes throughout the UK. The serial cross-sectional design does not address changes within the same cohort of students. This limited our ability to address whether some changes preceded others and might, therefore, be causal. However, this was not the intention of this study, which was designed to address serial cross-sectional trends in a public health context. The study also did not address exposure to PE or PA levels in or out of school in the individuals studied and cannot therefore directly address the possibility that declining CRF was caused by other declines in PAs. Nevertheless, we propose there is strong evidence that PE may be important for overall PA in this age group ${ }^{14} 15$ and flag the national evidence of declining exposure to $\mathrm{PE}^{29}$

\section{CONCLUSION}

This study is the first to report declining CRF, MC, muscle strength and power in recent years in a relatively large and diverse sample of UK adolescents. This has coincided with a drastic reduction in the number of taught $\mathrm{PE}$ lessons over the last decade. We also add evidence that muscle strength and power are declining quickest in adolescents with low fitness while CRF and MC are declining most in normal-weight adolescents. We suggest that a programme of monitoring should be a priority in all school-age children and adolescents and interventions could be swiftly established in schools, which focus on increasing PE lessons frequency and duration to reverse these adverse trends, thereby preventing expected, costly and serious adverse consequences for future population health.

Acknowledgements We would like to thank all three 0xfordshire schools that took part in this study and each of their Heads of Department for Physical Education. Their hard work on top of a very demanding schedule was greatly appreciated. In addition, we would like to thank all the students and staff within the Centre for Movement, Occupational and Rehabilitation Sciences (MOReS) at Oxford Brookes University for assisting with the data collection. Professor Helen Dawes is supported by the Elizabeth Carson Trust and the NIHR Oxford Biomedical Research Centre.

Contributors HD was the author acting as guarantor.

Funding Action Medical Research for Children (GN2445); Chartered Society of Physiotherapy Charitable Trust (GN2445); British Heart Foundation (FS/18/22/33479); Community Sport Activation Fund; PF Charitable Trust.

Disclaimer The views expressed are those of the authors and not necessarily those of the NHS, the NIHR or the Department of Health.

Competing interests None declared.

Patient consent for publication Not required.

Ethics approval This study involves human participants and was approved by the Oxford Brookes University Research Ethics Committee (UREC 140844 in 2014; 161033 in 2016) or the University of Oxford Medical Sciences Interdivisional Research Ethics Committee (MS IDREC R54302/RE001 in 2018), and the University of Oxford Central University Research Ethics Committee (CUREC R54302/RE005). Participants gave informed consent to participate in the study before taking part.

Provenance and peer review Not commissioned; externally peer reviewed.

Data availability statement No data are available. Due to ethical approval, which does not allow data sharing during or after the study, there are no data that can be shared.

Open access This is an open access article distributed in accordance with the Creative Commons Attribution Non Commercial (CC BY-NC 4.0) license, which permits others to distribute, remix, adapt, build upon this work non-commercially, and license their derivative works on different terms, provided the original work is properly cited, appropriate credit is given, any changes made indicated, and the use is non-commercial. See: http://creativecommons.org/licenses/by-nc/4.0/.

\section{ORCID iDs}

Benjamin David Weedon http://orcid.org/0000-0001-6983-5119

Samuel Joseph Burden http://orcid.org/0000-0003-1213-8878

Johnny Collett http://orcid.org/0000-0003-4138-2589

\section{REFERENCES}

1 DeFina LF, Haskell WL, Willis BL, et al. Physical activity versus cardiorespiratory fitness: two (partly) distinct components of cardiovascular health? Prog Cardiovasc Dis 2015;57:324-9.

2 Bull FC, Al-Ansari SS, Biddle S, et al. World Health organization 2020 guidelines on physical activity and sedentary behaviour. $\mathrm{Br} J$ Sports Med 2020;54:1451-62.

3 Hulteen RM, Morgan PJ, Barnett LM, et al. Development of foundational movement skills: a conceptual model for physical activity across the lifespan. Sports Med 2018;48:1533-40.

4 Robinson LE, Stodden DF, Barnett LM, et al. Motor competence and its effect on positive developmental trajectories of health. Sports Med 2015;45:1273-84.

5 Stodden DF, Goodway JD, Langendorfer SJ, et al. A developmental perspective on the role of motor skill competence in physical activity: an emergent relationship. Quest 2008;60:290-306.

6 Stodden DF, Gao Z, Goodway JD, et al. Dynamic relationships between motor skill competence and health-related fitness in youth. Pediatr Exerc Sci 2014;26:231-41.

7 Luz C, Cordovil R, Rodrigues LP, et al. Motor competence and health-related fitness in children: a cross-cultural comparison between Portugal and the United States. J Sport Health Sci 2019;8:130-6.

8 Imboden MT, Harber MP, Whaley MH, et al. Cardiorespiratory fitness and mortality in healthy men and women. J Am Coll Cardiol 2018;72:2283-92. 
9 Department for Education. Physical education programmes of study: key stages 3 and 4 national curriculum in England, 2013.

10 Fairclough S, Stratton G. 'Physical education makes you fit and healthy'. Physical education's contribution to young people's physical activity levels. Health Educ Res 2005;20:14-23.

11 Corder K, Winpenny E, Love R, et al. Change in physical activity from adolescence to early adulthood: a systematic review and meta-analysis of longitudinal cohort studies. Br J Sports Med 2019;53:496-503.

12 Remmers T, Van Kann D, Kremers S, et al. Investigating longitudinal context-specific physical activity patterns in transition from primary to secondary school using accelerometers, GPs, and GIS. Int $J$ Behav Nutr Phys Act 2020;17:1-14.

13 Sandercock GRH, Ogunleye A, Voss C. Six-Year changes in body mass index and cardiorespiratory fitness of English schoolchildren from an affluent area. Int J Obes 2015;39:1504-7.

14 Kerr C, Smith L, Charman S, et al. Physical education contributes to total physical activity levels and predominantly in higher intensity physical activity categories. Eur Phy Educ Rev 2018;24:152-64.

15 Meyer U, Roth R, Zahner L, et al. Contribution of physical education to overall physical activity. Scand J Med Sci Sports 2013;23:600-6.

16 Public Health England. Public Health Profile - Obesity Profile UK, 2020. Available: https://fingertips.phe.org.uk/profile/national-childmeasurement-programme [Accessed 08 Dec 2020].

17 Chung ST, Onuzuruike AU, Magge SN. Cardiometabolic risk in obese children. Ann N Y Acad Sci 2018;1411:166-83.

18 Friend A, Craig L, Turner S. The prevalence of metabolic syndrome in children: a systematic review of the literature. Metab Syndr Relat Disord 2013;11:71-80.

19 Reisinger C, Nkeh-Chungag BN, Fredriksen PM, et al. The prevalence of pediatric metabolic syndrome-a critical look on the discrepancies between definitions and its clinical importance. Int $J$ Obes 2021;45:12-24.

20 Chisholm D, Collis M, Kulak L. PAR-Q validation report: the evaluation of a self-administered pre-exercise screening questionnaire for adults. Victoria: Canada: BC Ministry of Health and Health and Welfare, 1978.

21 de Onis M, Onyango AW, Borghi E, et al. Development of a who growth reference for school-aged children and adolescents. Bull World Health Organ 2007;85:660-7.

22 Wind AE, Takken T, Helders PJM, et al. Is grip strength a predictor for total muscle strength in healthy children, adolescents, and young adults? Eur J Pediatr 2010;169:281-7.

23 Fernandez-Santos JR, Ruiz JR, Cohen DD, et al. Reliability and validity of tests to assess Lower-Body muscular power in children. $J$ Strength Cond Res 2015;29:2277-85.

24 Léger LA, Lambert J. A maximal multistage 20-m shuttle run test to predict VO2 max. Eur J Appl Physiol Occup Physiol 1982;49:1-12.

25 Léger LA, Mercier D, Gadoury C, et al. The multistage 20 metre shuttle run test for aerobic fitness. J Sports Sci 1988;6:93-101.

26 Mahmoud W, Delextrat A, Esser P, et al. A school-based screening tool for adolescents with low motor coordination abilities. Percept Mot Skills 2019;126:779-96.
27 Henderson S, Sugden D, Barnett A. Movement assessment battery for children-2: Movement ABC-2: Examiner's manual. San Antonio, TX: Pearson, 2007.

28 Psotta R, Abdollahipour R. Factorial validity of the movement assessment battery for Children-2nd edition (MABC-2) in 7-16-YearOlds. Percept Mot Skills 2017;124:1051-68.

29 Department for Education. Statistics: school workforce, 2020. Available: https://www.gov.uk/government/collections/statisticsschool-workforce [Accessed 22nd Oct 2020].

30 Little RJA. A test of missing completely at random for multivariate data with missing values. J Am Stat Assoc 1988;83:1198-202.

31 Peralta LR, Mihrshahi S, Bellew B, et al. Influence of School-Level socioeconomic status on children's physical activity, fitness, and fundamental movement skill levels. J Sch Health 2019;89:460-7.

32 National Perinatal Epidemiology Unit (NPEU), Nuffield Department of Population Health. Index of multiple deprivation tool: University of Oxford, 2013. Available: https://tools.npeu.ox.ac.uk/imd/12/8/2019

33 Sandercock GRH, Cohen DD. Temporal trends in muscular fitness of English 10-year-olds 1998-2014: an allometric approach. J Sci Med Sport 2019;22:201-5.

34 Stratton G, Canoy D, Boddy LM, et al. Cardiorespiratory fitness and body mass index of 9-11-year-old English children: a serial crosssectional study from 1998 to 2004. Int J Obes 2007;31:1172-8.

35 Fraser BJ, Blizzard L, Schmidt MD, et al. Childhood cardiorespiratory fitness, muscular fitness and adult measures of glucose homeostasis. J Sci Med Sport 2018;21:935-40.

36 Fraser BJ, Huynh QL, Schmidt MD, et al. Childhood muscular fitness phenotypes and adult metabolic syndrome. Med Sci Sports Exerc 2016;48:1715-22.

37 Fraser BJ, Schmidt MD, Huynh QL, et al. Tracking of muscular strength and power from youth to young adulthood: longitudinal findings from the childhood determinants of adult health study. J Sci Med Sport 2017;20:927-31.

38 Fraser BJ, Blizzard L, Buscot M-J, et al. The association between grip strength measured in childhood, Young- and Mid-adulthood and prediabetes or type 2 diabetes in Mid-adulthood. Sports Med 2021;51:175-83.

39 Kanavos P, van den Aardweg S, Schurer W. Diabetes expenditure, burden of disease and management in 5 EU countries. LSE Health and Social Care, 2012.

40 Durant N, Harris SK, Doyle S, et al. Relation of school environment and policy to adolescent physical activity. J Sch Health 2009;79:153-9.

41 Fu Y, Gao Z, Hannon J, et al. Influence of a health-related physical fitness model on students' physical activity, perceived competence, and enjoyment. Percept Mot Skills 2013;117:956-70.

42 Wilkie H, Standage M, Sherar L, et al. Results from England's 2016 report card on physical activity for children and youth. J Phys Act Health 2016;13:S143-9.

43 Beale N, Eldridge E, Delextrat A, et al. Exploring activity levels in physical education lessons in the UK: a cross-sectional examination of activity types and fitness levels. BMJ Open Sport Exerc Med 2021;7:e000924. 